\title{
RELATION BETWEEN SERUM LEVEL OF CALCIUM, PHOSPHORUS, AND VITAMIN D AND EARLY CHILDHOOD CARIES
}

\author{
Ahmed Othman Abd-Elhay Mansour ${ }^{(1)}$, Alaa Al-Deen Abdalla Mohamed Ismail ${ }^{(2)}$, Alaa Nabil Abbas ${ }^{(3)}$, \\ Ahmed Abd El-Rahman Sonbol ${ }^{(4)}$
}

\begin{abstract}
Objective: Early Childhood Caries (ECC) considers a multifactorial disease. Vitamin D, calcium, and phosphorus have a crucial role in mineralized tissue formation and mineralization. The purpose of this study was to evaluate the association between the serum level of vitamin D, calcium, and phosphorus, and ECC in healthy preschool children. Subject and methods: Thirtysix preschool children with ages from 1 to 6 years old were selected for this clinical study. Enrolled children were randomly divided into two equal groups ( $n=18)$; group I; children with ECC, group II; children with caries-free. Clinical examination was carried out to assess decay, missing, filled teeth (dmft) caries index using World Health Organization (WHO) criteria. 25-hydroxyvitamin D "25(OH)D”, calcium, and phosphorus in serum had been measured for all enrolled children.

Results: The results of this study showed a significant decrease in serum level of vitamin D, calcium, and phosphorus in children with ECC when compared to children with caries-free. However, the result of the $\mathrm{dmft}$ index revealed that the filled tooth due to caries showed a higher mean followed by decay and missing teeth. Conclusion: There is a relation between the deficiency in serum level of vitamin D, calcium, and phosphorus and the incidence of ECC.
\end{abstract}

KEYWORDS: Calcium, Early Childhood Caries, Phosphorus, Serum, Vitamin D

\section{INTRODUCTION}

Dental caries is one of the most prevalent diseases that occur in the mouth especially in children which could undermine the physical and psychological development as well as the general health of the child if left untreated ${ }^{(1)}$. ECC is an aggressive form of dental caries that is not a self-limiting disease ${ }^{(2)}$.

Commonly, ECC is defined as the presence of decayed "cavitated or non-cavitated" primary teeth, and/or presence of missing, or filled primary teeth due to caries in a child at 71 months of age or younger, regardless of being anterior or posterior ${ }^{(3,4)}$. ECC has various but unique clinical manifestations which include rapid caries development, affection of the tooth soon after they erupt, and involvement of the tooth surfaces that less likely to caries ${ }^{(3,5)}$.

ECC in their severe and mild form are multifactorial which influenced by health

1. Dentist, Ministry of Health, Egypt.

2. Associated Professor, Department of Pedodontics and Oral Health department Faculty of Dental Medicine, Boys, Cairo, Al-Azhar University.

3. Lecturer, Department Pedodontics and Oral Health department Faculty of Dental Medicine, Boys, Cairo, AlAzhar University.

4. Associated professor of clinical pathology Faculty of Medicine, Menoufia Universty

-Corresponding author: dentaosman9@gmail.com 
determinants and the environment. It is a complex disease apart from the classic etiological triad for caries $^{(6)}$. However, multiple risk factors could involve the occurrence and progression of ECC including; the lack of home routine oral hygiene, nature of infant feeding (breast or bottle feeding), frequency of brushing, frequent snacking, and socioeconomic status ${ }^{(2,7)}$.

Furthermore, a correlation was found between the severity of ECC and the level of parent's education, behavior, and dental knowledge ${ }^{(8)}$. It was found that; examining a child at the end of his/her first year after birth is a golden standard in the early identification, prevention, and/or intervention of ECC ${ }^{(9)}$.

Systemic factors could also significantly influence the occurrence and the severity of ECC. These systemic factors may include the maternal infections experienced by the mother, nutritional disorders, metabolic disease, and dietary deficiencies during pregnancy, and premature birth ${ }^{(10)}$.

Vitamins D is one of the important hormones that exist in the human body, and at the same time, it considers to be the essential vitamins of the body which is fat-soluble and can convert on exposure to sunlight to its active form 1,25hydroxycholecalciferol ${ }^{(11,12)}$. During primary tooth formation, the enamel, dentin, and cementum have a vascular system to supply nutrients that are required for mineralization which begins around 4 months in-utero ${ }^{(13)}$.

Vitamin D plays an important role in teeth development and mineralization through the deposition of calcium and phosphorus on tooth hard tissues via enhancement of the serum absorption of calcium and phosphorus from the intestines and decreasing their excretion from the kidneys (14). Additionally, vitamin D is responsible for maintaining normal serum calcium and phosphorus levels, and any imbalance or deficiency in their serum level will result in incomplete calcification and dental caries ${ }^{(15,16)}$.
Therefore, this clinical study was aimed to evaluate the correlation between the serum level of vitamin $\mathrm{D}$, calcium, and phosphorus and the presence of ECC in preschool-aged children between $1-6$ years.

\section{SUBJECT AND METHODS}

This study was conducted on thirty-six healthy children with early childhood caries or cariesfree. A child between the age group of 1 to 6 years was selected from kindergartens in Menoufia Governorate, Egypt.

All enrolled children were divided into two equal groups $(n=18)$ according to the cumulative score of (dmft) index as follow:

- Group I: Children with early childhood caries (study group).

- Group II: Children with caries-free $(\mathrm{dmft}=0)$ (control group).

\section{Patient Inclusion criteria:}

Parent and child cooperation, A systemic healthy children, 18 Children with ECC, 18 Children with caries-free $(\mathrm{dmft}=0)$ (control group), and Children age 1 - 6 years.

\section{Exclusion criteria:}

A history of any metabolic disease reported by parents, Children with a history of long-term medication, and children with radiotherapy or chemotherapy medication.

\section{Ethical Consideration:}

This study was carried out after approval of the ethical committee, Faculty of Dental Medicine, Al-Azhar University, Cairo, Boys (EC Ref No. 320/345/08/09/19). Permission was obtained from parent's/care givers for including their children in the study before starting the study.

After taking the informed consent, a complete medical and dental history was carried out by the 
dentist. The selected children were examined by using a mouth mirror and dental explorer under appropriate light conditions. The teeth were dried using cotton rolls, then the diagnosis regarding dmft index was gained according to the criteria of (WHO, 1987) ${ }^{(17)}$.

A complete child's data including name, gender and age, oral health practices, and dietary habits were collected from parent's/care givers using a structured questionnaire ${ }^{(18)}$.

\section{- Calculation of the dmft index:}

The dmft was assessed according to the WHO recommendations to calculate dental caries index ${ }^{(17)}$. The calculation of $\mathrm{dmft}$ was based on information of the decayed, missing, filled deciduous teeth. The dmf calculated as follows:

- d: included all teeth with code B- (decayed tooth) and C- (filled tooth with decay).

- m: included all teeth with code E- (teeth missing due to caries).

- $\quad \mathbf{f}$ : included teeth with code D- (filled teeth with no caries).

( $\mathrm{A}=$ sound, $\mathrm{B}=$ caries, $\mathrm{C}=$ filled with caries, $\mathrm{D}=$ filled with no caries, $\mathrm{E}=$ teeth missing due to caries)

\section{Blood samples collection:}

The blood samples were collected by a technician from the clinical pathology laboratory of Menoufia Universty Hospital at Shbeen El Kom.

$2 \mathrm{~mL}$ blood sample was collected from each child with a sterile disposable plastic syringe without any anticoagulant and analyzed in a laboratory for measuring vitamin $\mathrm{D}$, calcium, and phosphorus serum levels ${ }^{(19)}$.

\section{Biochemical analysis:}

The determination of 25-hydroxyvitamin D total in serum using VIDAS (BIOMERIEUX, Clinical Laboratory and Standards Institute, Inc, France) device, and ELFA technique (EnzymeLinked Fluorescent Assay) ${ }^{(19)}$. The serum calcium was determined by using a photometric test via using atomic absorption spectrophotometry at $570 \mathrm{~nm}$, using a commercial kit (Liquicolor human, Germany) ${ }^{(19)}$. The serum phosphorus was determined by ultraviolet (UV) colorimetry via UVvisible colorimetric method, using a commercial kit (Liquicolor human, Germany) ${ }^{(19)}$

\section{Statistical analysis:}

All data were collected, tabulated, and statistically analyzed using unpaired $t$-test, and chi-square test to compare the two groups at a $p<0.05$ level of significance.

\section{RESULTS}

\section{Sociodemographic background:}

The statistical analysis of sociodemographic background exhibited no statistical significance between the two studied groups regarding age, gender, birth rank, mother's occupation, father's occupation, and parent's/care givers education. While the results of the present study showed that caries-free children were more likely to be first borne compared to children with ECC as seen in (Table 1).

\section{Oral health practices:}

The statistical analysis revealed that the children with ECC were more likely to had previous dental visits compared to caries-free children. While children with caries-free were more likely to use tooth, brushing compared to children with ECC as seen in (Table 2). 
TABLE (1) Sociodemographic background of children with ECC and caries-free children.

\begin{tabular}{|c|c|c|c|c|c|}
\hline \multicolumn{2}{|c|}{ Variable } & Children with & Caries-free & $t$-value & $P$-value \\
\hline Age & 3-6 Years Mean (SD) & $4.21(0.80)$ & $4.36(0.74)$ & 0.4884 & 0.629362 \\
\hline \multirow{2}{*}{ Gender } & Male; n (\%) & $11(61.1)$ & $12(66.7)$ & \multirow{2}{*}{0.1204} & \multirow{2}{*}{0.7286} \\
\hline & Female $(\%)$ & $7(38.9)$ & $6(33.3)$ & & \\
\hline \multirow{3}{*}{ Birth rank } & $1^{\text {st. }}, \mathrm{n}(\%)$ & $9(50)$ & $12(66.7)$ & \multirow{3}{*}{1.2063} & \multirow{3}{*}{0.547072} \\
\hline & $2^{\text {nd. }} ; \mathrm{n}(\%)$ & $5(27.8)$ & $4(22.2)$ & & \\
\hline & Other; n (\%) & $4(22.2)$ & $2(11.1)$ & & \\
\hline \multirow{2}{*}{$\begin{array}{l}\text { Mother's } \\
\text { occupation }\end{array}$} & Housewife; n (\%) & $12(66.7)$ & $10(55.6)$ & \multirow{2}{*}{0.4675} & \multirow{2}{*}{0.494125} \\
\hline & Working; n (\%) & $6(33.3)$ & $8(44.4)$ & & \\
\hline \multirow{3}{*}{$\begin{array}{l}\text { Father's } \\
\text { occupation }\end{array}$} & Professional; n (\%) & $8(44.4)$ & $10(55.6)$ & \multirow{3}{*}{0.4991} & \multirow{3}{*}{0.77913} \\
\hline & Clerical; n (\%) & $7(38.9)$ & $6(33.3)$ & & \\
\hline & Laborer; n (\%) & $3(16.7)$ & $2(11.1)$ & & \\
\hline \multirow{3}{*}{ Parent education } & High; n (\%) & $12(66.7)$ & $16(88.9)$ & \multirow{3}{*}{2.5714} & \multirow{3}{*}{0.10880} \\
\hline & Middle; n (\%) & $6(33.3)$ & $2(11.1)$ & & \\
\hline & Illiterate; n (\%) & $0(0)$ & $0(0)$ & & \\
\hline
\end{tabular}

*: Statistically significant at $P \leq 0.05$.

TABLE (2) Oral health practices of children with ECC and caries-free children.

\begin{tabular}{|c|c|c|c|c|c|}
\hline & \multirow[t]{2}{*}{ Variable } & $\begin{array}{l}\text { Children with } \\
\text { ECC }\end{array}$ & $\begin{array}{c}\text { Caries-free } \\
\text { children }\end{array}$ & \multirow{2}{*}{$\begin{array}{l}\text { Chi-square } \\
\text { test value }\end{array}$} & \multirow[t]{2}{*}{$P$-value } \\
\hline & & Mean (SD) & Mean (SD) & & \\
\hline \multirow{2}{*}{$\begin{array}{l}\text { Previous dental } \\
\text { visits }\end{array}$} & Yes; n (\%) & $13(72.2)$ & $3(16.7)$ & \multirow{2}{*}{11.25} & \multirow{2}{*}{$0.000796^{*}$} \\
\hline & No; n $(\%)$ & $5(27.8)$ & $15(83.3)$ & & \\
\hline \multirow{2}{*}{ Brushing } & Yes; n (\%) & $5(27.8)$ & $12(66.7)$ & \multirow{2}{*}{5.4613} & \multirow{2}{*}{$0.019442 *$} \\
\hline & No; n $(\%)$ & $13(72.2)$ & $6(33.3)$ & & \\
\hline \multirow{3}{*}{$\begin{array}{l}\text { Brushing } \\
\text { frequency }\end{array}$} & One daily; n (\%) & $3(60)$ & $9(75)$ & \multirow{3}{*}{0.5431} & \multirow{3}{*}{0.762214} \\
\hline & Twice daily; n (\%) & $1(20)$ & $2(16.7)$ & & \\
\hline & More than twice daily; n (\%) & $1(20)$ & $1(8.3)$ & & \\
\hline \multirow{2}{*}{$\begin{array}{l}\text { Parental } \\
\text { supervision of } \\
\text { brushing }\end{array}$} & Yes; n (\%) & $2(40)$ & $8(66.7)$ & \multirow{2}{*}{1.0362} & \multirow{2}{*}{0.308709} \\
\hline & No; n $(\%)$ & $3(60)$ & $4(33.3)$ & & \\
\hline
\end{tabular}

*: Statistically significant at $P \leq 0.05$. 


\section{Dietary habits:}

The statistical analysis showed that caries-free children were more likely to breastfeeding compared to children with ECC but without a statistically significant difference. However, children with ECC were more likely to use sticky snacks compared to caries-free children but without a statistically significant difference as seen in (Table 3).

\section{dmft index:}

The dmft statistical analysis results showed that the children with ECC were more likely to had dental care for filling the decayed teeth with a mean and SD value of $(1.5 \pm 0.86)$. While children with ECC were less likely to had dental care for extraction with a mean and SD value of $(0.77 \pm 0.73)$ as seen in (Figure 1).

TABLE (3) Dietary habits of children with ECC and caries-free children.

\begin{tabular}{|c|c|c|c|c|c|}
\hline \multicolumn{2}{|c|}{ Variable } & $\begin{array}{c}\text { Children with } \\
\text { ECC }\end{array}$ & $\begin{array}{l}\text { Caries-free } \\
\text { children }\end{array}$ & \multirow{2}{*}{$\begin{array}{l}\text { Chi-square test } \\
\text { value }\end{array}$} & \multirow[t]{2}{*}{$P$-value } \\
\hline & & & & & \\
\hline \multirow{3}{*}{$\begin{array}{l}\text { Nursing } \\
\text { History }\end{array}$} & Breast; n (\%) & $8(44.4)$ & $9(50)$ & \multirow{3}{*}{0.1699} & \multirow{3}{*}{0.918542} \\
\hline & Bottle; n (\%) & $5(27.8)$ & $4(22.2)$ & & \\
\hline & Mixed; n (\%) & $5(27.8)$ & $5(27.8)$ & & \\
\hline \multirow{2}{*}{ Using sticky snacks } & Yes; n (\%) & $10(55.6)$ & $9(50)$ & \multirow{2}{*}{0.1115} & \multirow{2}{*}{0.73849} \\
\hline & No; n $(\%)$ & $8(44.4)$ & $9(50)$ & & \\
\hline \multirow{2}{*}{ Using sweetened juices } & Yes; n (\%) & $12(66.7)$ & $13(72.2)$ & \multirow{2}{*}{0.1309} & \multirow{2}{*}{0.71749} \\
\hline & No; n $(\%)$ & $6(33.3)$ & $5(27.8)$ & & \\
\hline
\end{tabular}

*: Statistically significant at $P \leq 0.05$.

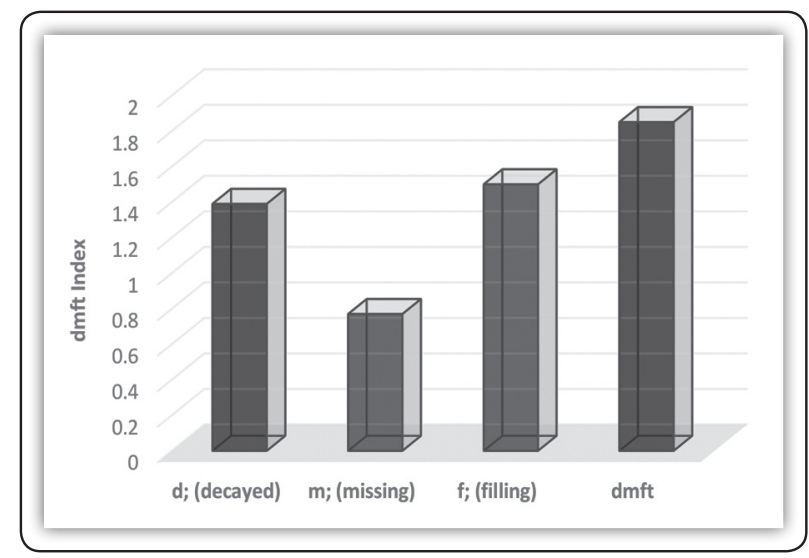

FIG (1) Illustrated diagram of mean values of dmft for children with ECC.

\section{Serum 25(OH)D, calcium, and phosphorus levels:}

The statistical analysis of $25(\mathrm{OH}) \mathrm{D}$, calcium, and phosphorus serum levels revealed a statistically significant difference between children with ECC and caries-free children as indicated by an unpaired t-test as seen in (Table 4). 
TABLE (4) Comparison of serum 25(OH)D, calcium, and phosphorus levels of children with ECC and caries-free children.

\begin{tabular}{|c|c|c|c|c|}
\hline \multirow{2}{*}{ Variable } & $\begin{array}{c}\text { Children } \\
\text { with ECC }\end{array}$ & $\begin{array}{c}\text { Caries-free } \\
\text { children }\end{array}$ & \multirow{2}{*}{$t$-value } & $P$-value \\
\cline { 2 - 3 } & Mean (SD) & Mean (SD) & & \\
\hline $\begin{array}{c}\text { Mean } \\
25(\mathrm{OH}) \mathrm{D} \\
(\mathrm{ng} / \mathrm{ml})\end{array}$ & $\begin{array}{c}24.43 \\
(11.14)\end{array}$ & $\begin{array}{c}44.29 \\
(14.65)\end{array}$ & 4.52907 & $0.000073^{*}$ \\
\hline $\begin{array}{c}\text { Total Ca } \\
(\mathrm{mg} / \mathrm{dl})\end{array}$ & $7.62(0.69)$ & $8.13(0.25)$ & 2.8842 & $0.006861^{*}$ \\
\hline $\begin{array}{c}\text { Phosphorus } \\
(\mathrm{mg} / \mathrm{dl})\end{array}$ & $4.88(0.44)$ & $5.22(0.47)$ & 2.20174 & $0.034783^{*}$ \\
\hline
\end{tabular}

*: Statistically significant at $P \leq 0.05$.

\section{DISCUSSION}

Various risk factors could contribute to the incidence of ECC such as sociodemographic background, the pattern of feeding, frequency of snack consumption, the status of oral hygiene, parent's educational level, and mother's working status ${ }^{(12,20)}$. Therefore, in the present study, we give attention to study factors that could contribute to this serious clinical problem.

In the present study, there was no significant difference between the children with ECC and cariesfree children concerning age, gender, and birth rank. This result proving that the two studied groups were correctly matched ${ }^{(7)}$. This per the results of Hussein et al., ${ }^{(18)}$ which concluded that both age and gender consider insignificant factors in the development of ECC. However, in their results, there was a significant difference according to the birth rank.

The results of the present study were agreed with the results of Jabbarifar et al., ${ }^{(21)}$ who did not report any significant relation between mother's work status and ECC. However, Quinonez et al., ${ }^{(22)}$ reported that; working mothers suffer stress at work, and may have less time to look after their children's oral hygiene, and found a strong association between mothers' working status and ECC.
Kuriakose et al., ${ }^{(23)}$ found a significant correlation between the previous dental visits and children with ECC. Additionally, Nobile et al., (24) showed that the prevalence of ECC was significantly higher in those who had visited a dentist in the previous year. This result was agreed with the results in the present study. This may be because; dentists were contacted only after ECC has occurred and that they do not play an active role in prevention ${ }^{(18)}$.

The results of the present study revealed a significant difference between caries-free children and children with early ECC concerning brushing. This may be due to parental assistance and guidance in cleaning children's teeth which is essential to reduce caries risk in preschool children ${ }^{(7,18)}$. However, this result was in disagreement with Abdel Aziz et al., ${ }^{(25)}$ who found that brushing was not significantly associated with ECC in preschool children.

In the present study, there was no statistically significant correlation between nursing history and the occurrence of caries. This agreed with the results of Perera et al., (26) who did not find a significant association between the nursing history and ECC in preschool children. However, this result was in disagreement with Hussein et al., ${ }^{(18)}$ who found a significant correlation between the nursing history and ECC.

It was reported that no significant association between ECC and the use of sticky snacks or sweetened juices ${ }^{(18)}$. This agreed with the results of the present study. However, Kuriakose et al., ${ }^{(23)}$ and Abdel Aziz et al., ${ }^{(25)}$ reported a significant association between caries and consumption of in-between meal snacks or sweetened juice and they recommended limiting snacking time with an emphasis on the quality of snacks.

The severity and prevalence of caries were established with the dmft score, commonly used in dental practice. This score has continuously been used by the National Health and Nutrition Examination Survey (NHANES) to assess caries prevalence ${ }^{(27)}$. Therefore, in the present study, we used the $\mathrm{dmft}$ score to assess the ECC. 
According to policy on ECC of the American Academy of Pediatric Dentistry (AAPD) $)^{(9)}$ and Chhonkar et al., ${ }^{(28)}$; vitamin D helps in the absorption of calcium and phosphorus from the intestine, and both calcium and phosphorus help in the mineralization of the teeth. This agreed with the results of the present study where the children with ECC have lower levels of vitamin $\mathrm{D}, \mathrm{Ca}$, and phosphorus in comparison to children with caries-free.

The combination between phosphorus and calcium plays a critical role in the ordered crystalline and mineralized structure of enamel to form hydroxyapatite and participating in ion transport during amelogenesis ${ }^{(29)}$. Disruptions in the formation of hydroxyapatite and ion exchanges result in hypomineralized enamel, which is soft and prone to caries. ${ }^{(30)}$ This supports the association between low serum phosphorus, calcium, and ECC in the present study.

The results of the present study exhibited an association between $25(\mathrm{OH}) \mathrm{D}$ levels and dental caries experience showed that children with $25(\mathrm{OH}) \mathrm{D}$ levels $24.43 \pm 11.14 \mathrm{ng} / \mathrm{mL}$ were 1.81 times more likely to have caries experience. This result was lower than the results of Schroth et al., ${ }^{(12)}$ that reported a 5.33-fold higher prevalence among young children with insufficient vitamin D.

Additionally, Aruna et al. (31), reported that the levels of calcium were found to be higher in patients who were free from caries as compared to those children with severe early childhood caries. This agreed with the results of this study whereas a significant difference in calcium level between the children with ECC and children with caries-free.

\section{CONCLUSION}

From the results of this study, it could be concluded that the deficiencies in vitamin D, calcium, and phosphorus serum level were accompanied by ECC. While the sociodemographic background had no significant effect on the presence of ECC.

\section{REFERENCES}

1. Parthasarathy P, Priya V, Gayathri R. Relationship between vitamin D and dental caries- Review. J Pharm Sci Res. 2016; 8: 459-60.

2. Zafar S, Harnekar SY, Siddiqi A. Early childhood caries: etiology, clinical considerations, consequences, and management. Int Dent SA. 2009; 11:24-36.

3. De Grauwe A, Aps J, Martens L. Early childhood caries (ECC): what's in a name? Eur J Paediatr Dent. 2004; 5:62-70.

4. Carino KMG, Shinida K, Kawaguchi Y. Early childhood caries in northern Philippines. Community Dent Oral Epidemiol. 2003; 31:81-89.

5. Feldens C, Giugliani E, Duncan B, Drachler M, Vitolo M. Long-term effectiveness of a nutritional program in reducing early childhood caries: a randomized trial. Community Dent Oral Epidemiol. 2010; 38:324-32.

6. Selwitz R H, Ismail A I, Pitts N B. Dental caries. Lancet. 2007;369: 51-59.

7. Schroth R J, Jeal N S, Kliewer E, Sellers EAC. The relationship between vitamin $\mathrm{D}$ and severe early childhood caries: A pilot study. Int J Vitam Nutr Res. 2012; 82:53-62.

8. Milgrom P, Riedy CA, Weinstein P, Tanner ACR, Manibusan L, Bruss J. Dental caries and its relationship to bacterial infection, hypoplasia, diet and oral hygiene in 6 to 36-month-old children Community Dent Oral Epidemiol 2000; 28: 295-306.

9. American Academy of Pediatric Dentistry. Policy on early childhood caries (ECC): classifications, consequences, and preventive strategies. Pediatr Dent. 2014; 36:50-2.

10. Caufield PW, Li Y, Bromage TG. Hypoplasia-as- sociated severe early childhood caries - a proposed definition. J Dent Res. 2012;91: 544-50.

11. Jalili Sadrabad M, Sohanian S. Evaluation of the relationship between serum level of Vitamin D and decayed, missing, and filled teeth (dmft) in young women in Semnan, Iran (2018-2019). J Sci Soc. 2020; 47:69-73.

12. Schroth R, Levi J, Sellers E, Friel J, Kliewer E, Moffatt M. Vitamin D status of children with severe early childhood caries: A case-control study. Biomed Central Pediatrics. 2013; 13:1-8.

13. Rathee M, Singla S, Tamrakar A T. Calcium and Oral Health: A Review. IJSR. 2013; 2: 335-8.

14. Holick MF. Sunlight and vitamin D for bone health and prevention of autoimmune diseases, cancers, and cardiovascular disease. Am J Clin Nutr. 2004; 80:1678-88. 
15. Brown T, Creed S, Alexender S, Barnard K, Bridges N, Hancock M. Vitamin D deficiency in children with dental caries- A prevalence study. Arch DIS Child. 2012;97: 103-7.

16. Shin Y, Shin H, Lee Y. Vitamin D status and childhood health. Korean J Pediatr. 2013; 56:417-23.

17. World Health Organization. Oral health surveys Basic Methods. 3rd ed. World Health Organization. Geneva: WHO; 1987.

18. Hussein YA, El-Tekeya MM, Dowidar KL, El-Tantawi M. Differences between children with early childhood caries and caries-free children in oral health habits: A case-control study. Alexandria Dent J. 2017; 42:28-32.

19. Gyll J, Ridell K, Öhlund I, Karlsland Åkeson P, Johansson I, Lif Holgerson P. Vitamin D status and dental caries in healthy Swedish children. Nutr J. 2018; 17:11-5.

20. Schroth RJ, Brothwell DJ, Moffatt ME. Caregiver knowledge and attitudes of preschool oral health and early childhood caries (ECC) Int J Circumpolar Health. 2007; 66:153-67.

21. Jabbarifar SE, Ahmady N, Sahafian SAR, Samei F, Soheillipour S. Association of parental stress and early childhood caries. Dent Res J. 2009; 6: 65-70.

22. Quinonez R, Keels M, Vann W Jr, McIver F, Heller K, Whitt J. Early childhood caries: analysis of psychosocial and biological factors in a high-risk population. Caries Res. 2000; 35: 376-83.

23. Kuriakose S, Prasannan M, Remya KC, Kurian J, Sreejith KR. Prevalence of early childhood caries among preschool children in Trivandrum and its association with various risk factors. Contemp Clin Dent. 2015; 6: 69-73.
24. Nobile CGA, Fortunato L, Bianco A, Pileggi C, Pavia M. Pattern and severity of early childhood caries in Southern Italy: a preschool-based cross-sectional study. BMC Public Health. 2014; 14:206-18.

25. Abdel Aziz WE, Dowidar KM, El Tantawi MM. Association of healthy eating, juice consumption, and bacterial counts with early childhood caries. Pediatr Dent. 2015; 37:462-7.

26. Perera PJ, Fernando MP, Warnakulasooriya TD, Ranathunga N. Effect of feeding practices on dental caries among preschool children: a hospital-based analytical cross-sectional study. Asia Pac J Clin Nutr. 2014; 23:272-7.

27. Dye BA, Tan S, Smith V, Lewis BG, Barker LK, Thornton-Evans G, et al. Trends in oral health status: the United States, 1988-1994 and 1999-2004. National Center for Health Statistics Vital Health Stat. 2007; 11-5.

28. Chhonkar A, Gupta A, Arya V. Comparison of Vitamin D Level of Children with Severe Early Childhood Caries and Children with No Caries. Int J Clin Pediatr Dent. 2018; 11:199-204.

29. Lacruz R, Habelitz S, Wright J, Paine M. Dental Enamel Formation and Implications for Oral Health and Disease. Physiol Rev. 2017; 97: 939-93.

30. Schroth RJ, Dhalla S, Tate R, Moffatt MEK. Prenatal and early childhood determinants of enamel hypoplasia in infants. J Pediatr Perinatol Child Health. 2021; 5: 5-17.

31. Aruna S, Meenakshi B, Rama KV, Valarmathi S. Salivary levels of calcium and phosphorus in children with and without early childhood caries: A pilot study. SRM J Res Dent Sci. 2020; 11:72-5. 